\title{
Quantitative developments in financial volatility-theory and practice
}

\author{
Elisa Alòs ${ }^{1} \cdot$ Maria Elvira Mancino ${ }^{2} \cdot$ Tai-Ho Wang $^{3}$ \\ Published online: 31 October 2019 \\ (c) Associazione per la Matematica Applicata alle Scienze Economiche e Sociali (AMASES) 2019
}

The notion of volatility is ubiquitous in all areas of social sciences including economics, finance, insurance, and management. The modeling, inference, and forecast of volatility is by all means of paramount importance. The journal of Decision in Economics and Finance is thus introducing a special issue on quantitative developments in financial volatility in order to promote and advance the already growing scientific publications as well as to provide deeper theoretical results and implementation tools on financial volatility, for both academics and practitioners.

The journal's motivation of editing a special issue on volatility came from the inspirational invited and contributed talks at the 2017 A.M.A.S.E.S. Conference held in Cagliari. This special issue, entitled Quantitative developments in financial volatilitytheory and practice, invited leading experts to share their deep and inspirational reviews on the subject and encouraged researchers from academia and industry to contribute their recent research articles. All the papers have gone through the journal's regular refereeing process under the same standards set by the journal. Among a number of submitted papers, fourteen were accepted for publication in this special issue.

The topics involved in the collected papers, though much biased to our own preferences, range from statistical estimation and inference of instantaneous and integrated volatilities, volatility modeling and calibration, to the pricing of financial derivatives on volatilities. We also include an introductory article in this special issue to illustrate in more details how the papers fit into the recent stream of researches on volatility. It

\footnotetext{
$凶$ Elisa Alòs

elisa.alos@upf.edu

Maria Elvira Mancino

mariaelvira.mancino@unifi.it

Tai-Ho Wang

tai-ho.wang@baruch.cuny.edu

1 Dep. Economia i Empresa and Barcelona Graduate School of Economics, Universitat Pompeu Fabra, Barcelona, Spain

2 Dipartimento di Scienze per l'Economia e l'Impresa, Università degli Studi di Firenze, Firenze, Italy

3 Department of Mathematics, Baruch College, City University of New York, New York, USA
} 
is our intention that the introduction of this special issue would lead to a new wave of research on volatility and its related topics. Last but definitely not least, we would like to express our gratitude to all the referees who helped reviewing and improving the manuscripts.

Publisher's Note Springer Nature remains neutral with regard to jurisdictional claims in published maps and institutional affiliations. 